\title{
Effects of Atrial Natriuretic Peptide and Vasopressin on Chloride Transport in Long- and Short-looped Medullary Thick Ascending Limbs
}

\author{
Hiroshi Nonoguchi, Kimio Tomita, and Fumiaki Marumo \\ Second Department of Internal Medicine, Tokyo Medical and Dental University, Tokyo 113, Japan
}

\begin{abstract}
Recent studies have suggested a selective effect of atrial natriuretic peptide (ANP) in regulating $\mathrm{NaCl}$ reabsorption in juxtamedullary nephrons. We examined $(a)$ functional differences between medullary thick ascending limbs from long and short loops of Henle (IMAL and SMAL, respectively) and (b) the interaction of ANP and arginine vasopressin (AVP) on $\mathrm{Cl}^{-}$ transport $\left(J_{C l}\right)$ in these two segments. AVP-, glucagon-, and calcitonin-stimulated cAMP accumulation was higher in IMAL than in SMAL. $10^{-10} \mathrm{M} A V P$ increased $J_{C}$ in IMAL but not in sMAL. ANP-stimulated cGMP production was higher in IMAL than in SMAL. $10^{-10}$ and $10^{-8} \mathrm{M}$ ANP inhibited AVPstimulated $J_{\mathrm{Cl}}$ in IMAL by $26-30 \%$ (from $70.3 \pm 11.4$ to 51.7 $\pm 13.6 \mathrm{pmol} / \mathrm{mm}$ per $\mathrm{min}$ and from $88.1 \pm 10.1$ to 61.8 $\pm 11.7 \mathrm{pmol} / \mathrm{mm}$ per $\mathrm{min}$, respectively), and this effect was mimicked by $10^{-5}$ to $10^{-4} \mathrm{M}$ cGMP. This effect of ANP in IMAL could account for a large part of the ANP-induced natriuresis and diuresis in vivo, in that the rate of $\mathrm{NaCl}$ reabsorption in MAL is the largest among distal nephron segments, providing the chemical potential energy for the renal countercurrent multiplication system. (J. Clin. Invest. 1992.90:349-357.) Key words: atrial natriuretic peptide $\bullet$ chloride transport $\bullet$ long and short loop nephron • medullary thick ascending limb • vasopressin
\end{abstract}

\section{Introduction}

Acting through cyclic GMP (cGMP), atrial natriuretic peptide (ANP) ${ }^{1}$ causes numerous important physiological effects, such as natriuresis, diuresis, smooth muscle relaxation, and a decrease in blood pressure (1-4). However, the mechanism of the natriuresis and diuresis caused by ANP is still incompletely understood (5). The chief target sites for ANP in the kidney

A portion of this study was presented at the 22nd Annual Meeting of the American Society of Nephrology, Washington, DC, December 1989 and has appeared in abstract form (1990. Kidney Int. 37:586).

Address reprint requests to Dr. Nonoguchi, Second Department of Internal Medicine, Tokyo Medical and Dental University, 1-5-45 Yushima, Bunkyo-ku, Tokyo 113, Japan.

Received for publication 28 February 1991 and in revised form 18 February 1992.

1. Abbreviations used in this paper: ANP, atrial natriuretic peptide; AVP, arginine vasopressin; CCD, cortical collecting duct; IMCD, inner medullary collecting duct; $J_{\mathrm{C}}$, chloride transport (flux ); MAL, medullary thick ascending limb of Henle's loop; similarly, IMAL and sMAL, MAL from long and short loops of Henle; PD, potential difference.

J. Clin. Invest.

(c) The American Society for Clinical Investigation, Inc. 0021-9738/92/08/0349/09 \$2.00

Volume 90, August 1992, 349-357 have been considered to be glomeruli and inner medullary collecting ducts (IMCD) (1-5). ANP increases the glomerular filtration rate (1-4) and inhibits water and $\mathrm{Na}$ reabsorption in IMCD (6-11). ANP also inhibits water and $\mathrm{NaCl}$ reabsorption in cortical collecting ducts (CCD) $(12,13)$, but those effects may not fully explain ANP-induced natriuresis and diuresis (5). Micropuncture studies have suggested an action site upstream of the IMCD and the possibility that ANP selectively inhibits $\mathrm{NaCl}$ reabsorption in juxtamedullary nephrons (7, 14), that is, in the subpopulation of nephrons with long loops of Henle that reach into the inner medulla. The medullary thick ascending limb of Henle's loop (MAL) has the largest ability to absorb $\mathrm{NaCl}$ among distal nephron segments (15) and provides the chemical potential energy that drives the renal countercurrent multiplication system. However, MAL was reported to be insensitive to ANP in rabbits, when ANP was applied to nonstimulated tubules (16).

Arginine vasopressin (AVP), a key hormone for urine concentration, has been reported to stimulate adenylate cyclase in MAL of rodents (17) and $\mathrm{NaCl}$ transport in MAL of the mouse and the Brattleboro rat, but not in the human and the rabbit (18-21). There are two types of MAL: that from long and from short loops of Henle (IMAL and sMAL, respectively). The ratio of long to short loops of Henle differs among species. Humans and rats have more short loops than long loops, whereas rabbits have more long loops than short loops (22, 23). Functional differences between IMAL and sMAL have not yet been demonstrated. Some of the action of ANP is caused by interaction with other hormones. ANP has been reported to inhibit AVP action in collecting ducts $(6,12,13)$. However, there are no reports concerning interaction of ANP and AVP in MAL. We hypothesized that: $(a)$ there is internephron heterogeneity in MAL; IMAL and SMAL exhibit distinct regulation of transport functions, especially by AVP; and (b) a portion of the natriuretic action of ANP may be due to inhibition of AVP-stimulated $\mathrm{NaCl}$ reabsorption in one or more of these segments. Consequently, we investigated the functional differences between IMAL and sMAL, and the interaction of ANP and AVP on $\mathrm{Cl}^{-}$transport $\left(J_{\mathrm{Cl}}\right)$ in these two segments of rats.

\section{Methods}

Pathogen-free male Sprague-Dawley rats weighing 50-100 g were obtained from Japan Laboratory Animals Inc. (Tokyo). AVP, salmon calcitonin, glucagon, cGMP, dibutyryl cyclic AMP (dibutyryl cAMP), and collagenase were purchased from Sigma Chemical Co. (St. Louis, MO). ANP was obtained from Peptide Institute (Osaka, Japan). Other chemicals were of the first grade.

Peptide hormone-dependent cAMP and cGMP accumulation. cAMP accumulations stimulated by AVP, salmon calcitonin, and glucagon, and CGMP accumulation stimulated by ANP, were compared between IMAL and SMAL. Rats were killed by decapitation and the left kidney was perfused with $10 \mathrm{ml}$ of ice-cold dissection solution contain- 
ing $1 \mathrm{mg} / \mathrm{ml}$ collagenase (type $1,300 \mathrm{U} / \mathrm{mg}$ ) and $1 \mathrm{mg} / \mathrm{ml} \mathrm{BSA}$. Coronal slices were incubated in the dissection solution containing collagenase for $30 \mathrm{~min}$ at $37^{\circ} \mathrm{C}$ under aeration with $100 \% \mathrm{O}_{2}$. After the incubation, the slices were washed with the dissection solution. Microdissection was performed using needles under a stereomicroscope at $6-8^{\circ} \mathrm{C}$ in the dissection solution containing $0.05 \%$ BSA.

IMAL and SMAL were dissected from the inner stripe of the outer medulla. Fig. 1 is a photograph of microdissected MAL and sMAL. IMAL was confirmed by the attachment of the thin ascending limb, which comes from the inner medulla. sMAL was identified by the bend and by the attachment of the thin descending limb, which comes from the outer stripe of the outer medulla. sMAL was consistently larger in diameter than IMAL. The thin ascending limbs were much thicker than the thin descending limbs.

The dissection solution had the following composition (in $\mathrm{mM}$ ): $130 \mathrm{NaCl}, 5 \mathrm{KCl}, 1 \mathrm{NaH}_{2} \mathrm{PO}_{4}, 1 \mathrm{MgSO}_{4}, 1 \mathrm{Ca}$ lactate, $2 \mathrm{Na}$ acetate, 5.5 glucose, $5 \mathrm{~L}$-alanine, $2 \mathrm{~L}$-leucine, $10 \mathrm{Hepes} ; \mathrm{pH}$ was adjusted to 7.4 by adding $\mathrm{NaOH}$.

After microdissection, tubular length was measured by means of an ocular micrometer. A 5- to 10-mm-long $1 M A L$ or $\mathrm{MMAL}$ was used for a single determination of cAMP content. A 30- to 80-mm-long IMAL or sMAL was used for a single determination of CGMP content.

We used previously described procedures $(24,25)$ for the measurement of cyclic nucleotide contents. Microdissected IMAL and SMAL were transferred with $2 \mu \mathrm{l}$ of the dissection solution containing $0.05 \%$ BSA, using a siliconized glass pipette, into $1.5-\mathrm{ml}$ plastic centrifuge tubes containing $18 \mu \mathrm{l}$ of the dissection solution with $0.5 \mathrm{mM}$ 3-isobu-

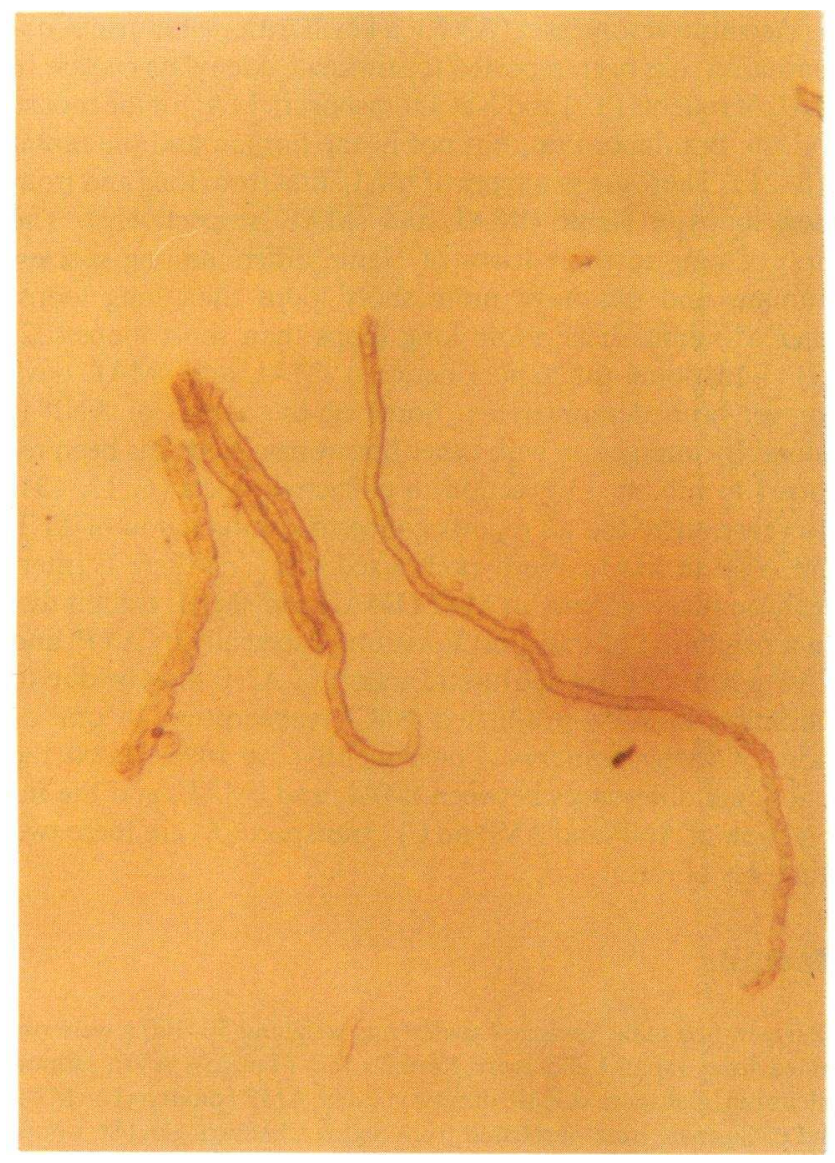

Figure 1. A photograph of IMAL (right) and SMAL (middle). Two sMAL are shown in the middle. The outer medullary collecting duct from the inner stripe of the outer medulla is shown at the left for comparison. IMAL and SMAL were dissected after collagenase treatment of kidney slices $(24,25)$. Note that the sMAL begins just before the bend and is thicker than the MAL. tyl-1-methylxanthine. The samples were incubated for $10 \mathrm{~min}$ at $37^{\circ} \mathrm{C}$ before the addition of peptide hormone (AVP, salmon calcitonin, glucagon, or ANP). After a 3-min incubation, the reaction was stopped by the addition of $50 \mu \mathrm{l}$ of ice-cold trichloroacetic acid (TCA). Each tube was centrifuged for $5 \mathrm{~min}$ at $3,000 \mathrm{rpm}$ at $4^{\circ} \mathrm{C}$. $75 \mu \mathrm{l}$ of supernatant was stored at $-20^{\circ} \mathrm{C}$ until the assay of cyclic nucleotide. Blank samples containing medium and TCA without nephron segments were also stored for use as standards in each experiment.

Frozen samples were thawed at room temperature, and TCA was extracted by water-saturated ether. Samples were dried, and $100 \mu \mathrm{l}$ of $50 \mathrm{mM}$ sodium acetate buffer ( $\mathrm{pH} 6.2)$ was added. cAMP (2.5-1,000 fmol) and cGMP (0.5-1,000 fmol) standards in $50 \mathrm{mM}$ sodium acetate buffer were added to blank samples. Samples and standards were acetylated and assayed for CAMP or CGMP by using radioimmunoassay kits (New England Nuclear, Boston, MA).

Na-K-ATPase activity. Na-K-ATPase activity in IMAL and SMAL was determined as described previously with a slight modification (26). Briefly, dissected IMAL and SMAL were stored in $10 \mu \mathrm{l}$ of solution and permeabilized by freeze-thawing. $10 \mu \mathrm{l}$ of incubation medium was added to each sample. The final composition of the incubation medium was as follows (in $\mathrm{mM}$ ): $120 \mathrm{NaCl}, 10 \mathrm{KCl}, 100$ imidazole, 5 $\mathrm{MgCl}_{2}, 1$ EGTA, $10 \mathrm{Na}_{2} \mathrm{AT}, \mathrm{P}, 20$ phosphoenolpyruvate, 2 ascorbic acid, $2 \mathrm{NADH}, 2.8 \mathrm{U} / \mathrm{ml}$ pyruvate kinase, $4 \mathrm{U} / \mathrm{ml}$ lactate dehydrogenase; $\mathrm{pH}$ 7.0. $\mathrm{NaCl}$ and $\mathrm{KCl}$ were replaced by $130 \mathrm{mM}$ choline $\mathrm{Cl}$, and $1 \mathrm{mM}$ ouabain was added for the assay of ouabain-insensitive ATPase activity. Each sample was incubated for $10 \mathrm{~min}$ at $37^{\circ} \mathrm{C}$, and the reaction was stopped by the addition of $20 \mu \mathrm{l}$ of $0.5 \mathrm{~N} \mathrm{HCl}$. After $20 \mathrm{~min}$ at room temperature, $40 \mu \mathrm{l}$ of acidified sample was transferred to $600 \mu \mathrm{l}$ of $6 \mathrm{~N} \mathrm{NaOH}$ and immediately mixed. The tube was placed at $60^{\circ} \mathrm{C}$ for 60 min in the dark, to convert the NAD to a condensed form of NAD. The fluorescence in each tube was measured. Various amounts of ADP were added to an incubation medium for use as standards.

Because $J_{\mathrm{Cl}}$ decreased with time in both IMAL and sMAL in the absence of AVP (see Results), we also examined whether Na-K-ATPase activity decreases with time. IMAL or SMAL was incubated in perfusion solution (see below) for $30 \mathrm{~min}$ at $37^{\circ} \mathrm{C}$ in the presence of $5 \%$ $\mathrm{CO}_{2}-95 \% \mathrm{O}_{2}$. Na-K-ATPase activity was compared before and after the incubation in both IMAL and SMAL.

A 5- to 10-mm-long IMAL or SMAL was used for a single determination of Na-K-ATPase activity. Total ATPase activity was determined in the absence of ouabain, and ouabain-insensitive ATPase activity was determined in the presence of $1 \mathrm{mM}$ ouabain. Na-K-ATPase activity was determined as the ouabain-sensitive ATPase activity (total ATPase activity minus ouabain-insensitive ATPase activity).

Fluid transport study using isolated tubule perfusion. MAL has been reported to be impermeable to water $(18-21,27)$. The absence of fluid absorption in IMAL and SMAL was examined using isolated tubule perfusion $(13,28)$. IMAL or SMAL was obtained without collagenase treatment. Rats were decapitated and coronal slices of the kidneys were used for dissection. The dissection solution was the same as mentioned above, and it was continuously gassed with $100 \% \mathrm{O}_{2}$. IMAL or sMAL was dissected with forceps and perfused in vitro at $37^{\circ} \mathrm{C}$. The perfusion solution and the bath solution were identical and had the following composition (in $\mathrm{mM}$ ): $118 \mathrm{NaCl}, 25 \mathrm{NaHCO}_{3}, 2.5 \mathrm{~K}_{2} \mathrm{HPO}_{4}$, $1 \mathrm{MgSO}_{4}, 1 \mathrm{Ca}$ lactate, $2 \mathrm{Na}$ acetate, 5.5 glucose, $5 \mathrm{~L}$-alanine, $2 \mathrm{~L}$-leucine. The solution was continuously gassed with $5 \% \mathrm{CO}_{2}-95 \% \mathrm{O}_{2}$. To measure fluid transport, $10 \mathrm{mM}$ creatinine was added to both the perfusate and the bath solution (13). In this experiment, tubules were perfused at slow flow rates ( $1-2 \mathrm{nl} / \mathrm{mm}$ per $\mathrm{min}$ ). The creatinine concentrations in the perfusate, bath, and the collected fluid were measured by using a continuous-flow ultramicrocolorimeter (Otsuka Electronics, Osaka) (29). The rate of fluid absorption was calculated as $J_{\mathbf{v}}$ $=\left(X_{\mathrm{L}} / X_{\mathrm{O}}-1\right) V_{\mathrm{L}} / L$, where $X_{\mathrm{L}}$ is the concentration of creatinine in the collected fluid, $X_{\mathrm{O}}$ is the concentration of creatinine in the perfusate, $V_{\mathrm{L}}$ is the rate at which fluid is collected at the end of the tubule, and $L$ is the tubule length.

Net chloride transport study using isolated tubule perfusion. The effects of AVP and ANP on the net chloride absorption and potential 
difference (PD) in IMAL and SMAL were studied by using the same isolated tubule perfusion as in the fluid transport study. Tubules were perfused at relatively fast flow rates $(5-15 \mathrm{nl} / \mathrm{mm}$ per min $)$.

At first, the change of $J_{\mathrm{C}}$ with time was examined in both IMAL and sMAL. Then, the effect of AVP on $J_{\mathrm{C}}$ was examined both in IMAL and in SMAL. Tubules were perfused and bathed in the same solution at $37^{\circ} \mathrm{C}$. Usually $\sim 45-90 \mathrm{~min}$ for $\mathrm{MMAL}$ and $20-60 \mathrm{~min}$ for SMAL were allowed for equilibration, in that the decrease of $J_{\mathrm{C}}$ with time was larger in SMAL than in IMAL. After two to five collections, $10^{-10} \mathrm{M}$ AVP was added only to the bath. Two to five experimental collections were made after 15-20 min. Next, the effect of ANP on $J_{\mathrm{C}}$ was studied in the absence of AVP. After control collections, $10^{-8} \mathrm{M}$ ANP was added only to the bath. Finally, the effect of ANP was examined in the presence of AVP. For SMAL, $10^{-10} \mathrm{M}$ AVP was added to the bath from the beginning. After control collections, $10^{-8} \mathrm{M}$ ANP or vehicle was added to the bath. Experimental collections were started after $15 \mathrm{~min}$. For IMAL, $10^{-10} \mathrm{M}$ AVP was added to the bath at 45-90 min after starting perfusion. After the collections of control samples, $10^{-8} \mathrm{M}$ ANP or vehicle was added only to the bath. Experimental collections were made after 15-20 min. Then ANP was removed from the bath and recovery samples were collected after 15-20 min. For the vehicle group, recovery collection was not performed (two-phase experiment). Total experimental time was 120-210 min for each tubule. The reason for the relatively longer experimental time for MAL was that we had to wait at least $45 \mathrm{~min}$ before the addition of AVP to see the effect of AVP on PD (see Fig. 7). When we added AVP to the bath at an earlier time after starting the perfusion, it was difficult to see the effect of AVP on PD in IMAL. It may take time to wash out intrinsic AVP. A lower dose of ANP $\left(10^{-10} \mathrm{M}\right)$ was tested in the presence of $5 \times 10^{-11} \mathrm{M}$ AVP only in IMAL, because $10^{-8} \mathrm{M}$ ANP was effective only in IMAL (see Results). When the effect of cGMP was tested, $10^{-4}$ or $10^{-5} \mathrm{M}$ cGMP was added only to the bath.

Chloride concentrations in the perfusate, bath, and the collected fluid were measured using a free-flow ultramicrocolorimeter (Otsuka Electronics) (30). In that there was no fluid transport in both IMAL and sMAL (see Results), net $J_{\mathrm{C} 1}$ was calculated as $J_{\mathrm{C}}=\left(C_{\mathrm{o}}-C_{\mathrm{L}}\right) V_{\mathrm{L}} /$ $L$, where $C_{\mathrm{O}}$ and $C_{\mathrm{L}}$ are the chloride concentration in the collected fluid and perfusate, respectively.

Statistics. Two to five measurements were averaged to obtain a single value for each experimental condition in each tubule. Results are shown as means \pm SE. Student's $t$ test or analysis of variance was employed for statistical analysis. A $P<0.05$ was considered statistically significant.

\section{Results}

Effects of peptide hormone on cAMP or cGMP accumulation in IMAL and $S M A L$. AVP, glucagon, and salmon calcitonin showed much larger effects on cAMP accumulation in IMAL than in sMAL (Fig. 2). Salmon calcitonin did not stimulate cAMP accumulation in SMAL. The effect of ANP on cGMP accumulation was much larger in IMAL than in SMAL $(0.10 \pm 0.05$ and $0.04 \pm 0.006 \mathrm{fmol} / \mathrm{mm}$ per $3 \mathrm{~min}$ in $1 \mathrm{MAL}$ and sMAL, respectively, $n=10, P<0.05$ [Fig. 3]. Without ANP, cGMP accumulation was $0.01 \pm 0.005$ and $0.009 \pm 0.004 \mathrm{fmol} /$ $\mathrm{mm}$ per min in IMAL and SMAL, respectively). Without IBMX, cGMP accumulation was not detectable, even in the presence of ANP.

Na-K-ATPase activity in IMAL and SMAL. Na-K-ATPase activity in IMAL was significantly higher than that in SMAL $(85.3 \pm 10.7$ and $70.8 \pm 8.8 \mathrm{pmol} / \mathrm{mm}$ per $\mathrm{min}$ in $\mathrm{MAL}$ and sMAL, respectively, $n=6, P<0.05$ [Fig. 4]). Na-K-ATPase activity did not decrease after a 30 -min incubation in perfusion solution both in IMAL and SMAL (from 86.4 \pm 15.7 to $78.6 \pm 5.3 \mathrm{pmol} / \mathrm{mm}$ per min in $\mathrm{MAL}, n=5, P>0.05$, and
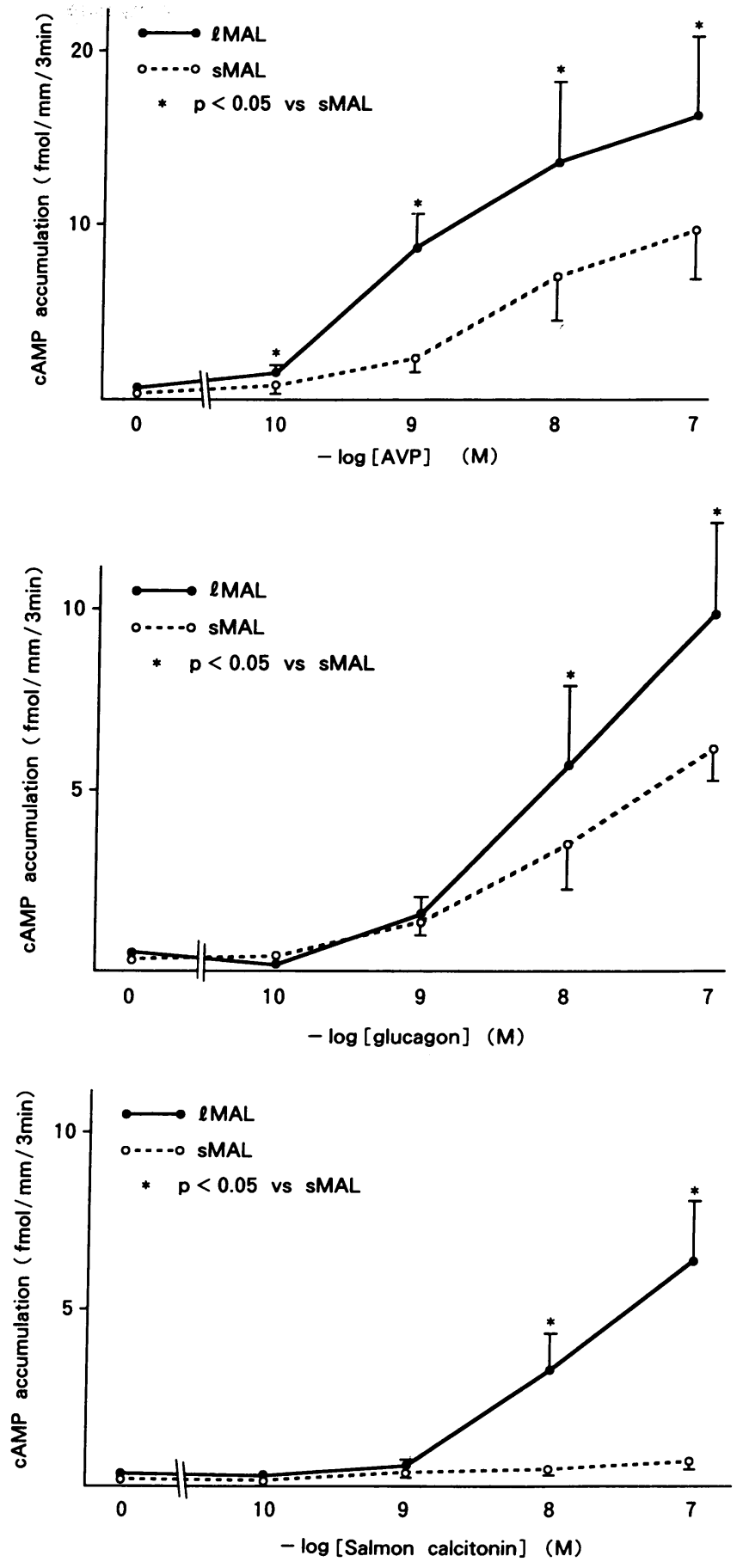

Figure 2. Effect of (top) AVP, (middle) glucagon, and (bottom) salmon calcitonin on CAMP accumulation in IMAL (solid lines) and sMAL (dashed lines). Tubules were incubated with hormone for 3 min at $37^{\circ} \mathrm{C}$. Values are mean \pm SE. and $n=6-16$ for each point. ${ }^{*} P$ $<0.05$ vs SMAL by paired $t$ test.

from $60.3 \pm 11.3$ to $74.3 \pm 12.0 \mathrm{pmol} / \mathrm{mm}$ per $\min$ in $\mathrm{sMAL}, n$ $=5, P>0.05$ ).

Fluid transport in IMAL and SMAL. We confirmed the absence of a fluid flux in IMAL and SMAL $(-0.003 \pm 0.006$ and $-0.002 \pm 0.005 \mathrm{nl} / \mathrm{mm} / \mathrm{min}$ in $\mathrm{MAL}$ and sMAL, respectively, $n=4-6$. Both values were not statistically different from zero, $P>0.05$ ). 


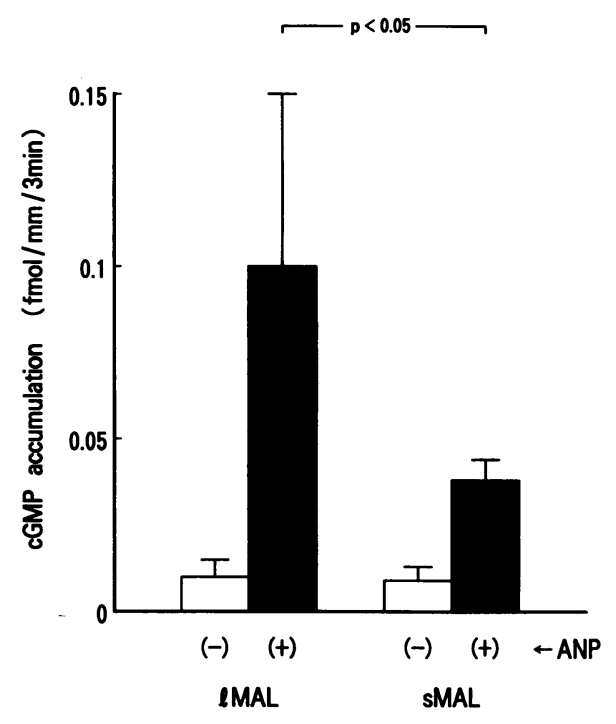

Figure 3. Effect of ANP $\left(10^{-6} \mathrm{M}\right)$ on cGMP accumulation in IMAL and SMAL. Tubules were incubated with or without ANP for $3 \mathrm{~min}$ at $37^{\circ} \mathrm{C}$. ANP-stimulated cGMP accumulation in IMAL was higher than that in SMAL.

Effect of AVP on $J_{C l}$ and PD in IMAL and sMAL (Table I). $J_{\mathrm{Cl}}$ decreased with time in both $\mathrm{MAL}$ and SMAL (series 1 of Table I, left panel of Figs. 5 and 6) (from $51.5 \pm 12.1$ to $32.6 \pm 5.1 \mathrm{pmol} / \mathrm{mm}$ per min in $1 \mathrm{MAL}, P>0.05$, and from $82.8 \pm 14.5$ to $51.4 \pm 6.3 \mathrm{pmol} / \mathrm{mm}$ per min in sMAL, $P$ $<0.05)$. This decrease of $J_{\mathrm{C} 1}$ with time was larger in sMAL than in IMAL. Typical experiments of the effect of AVP on PD are shown in Fig. 7. 10 $0^{-10} \mathrm{M}$ AVP significantly increased $J_{\mathrm{Cl}}$ (from $70.8 \pm 9.2$ to $107.8 \pm 11.0 \mathrm{pmol} / \mathrm{mm}$ per $\min , n=23, P$ $<0.001$ ) and PD (from $2.6 \pm 0.2$ to $3.3 \pm 0.3 \mathrm{mV}, n=25, P$ $<0.001$ ) in IMAL (series 2 of Table I, middle panel of Fig. 5). In contrast, both values fell in SMAL after AVP addition, as in the time controls $\left(J_{\mathrm{C}}\right.$, from $109.8 \pm 24.6$ to $75.4 \pm 16.3 \mathrm{pmol} /$ $\mathrm{mm}$ per min, $n=10, P<0.02$; and $\mathrm{PD}$, from $3.2 \pm 0.5$ to $2.8 \pm 0.7 \mathrm{mV}, P>0.05$ ) (series 2 of Table I, middle panel of Fig. $6)$. The decrease of $J_{\mathrm{Cl}}$ in AVP-treated tubules in SMAL was not statistically different from time controls $(P>0.05$ by analysis of variance) $10^{-4} \mathrm{M}$ dibutyryl cAMP also increased $J_{\mathrm{Cl}}$ in IMAL (from $43.6 \pm 8.4$ to $68.3 \pm 17.8 \mathrm{pmol} / \mathrm{mm}$ per $\min , n=8$, $P<0.05$ ) but not in sMAL (from $63.6 \pm 8.5$ to $62.3 \pm 12.3$ $\mathrm{pmol} / \mathrm{mm}$ per min, $n=7, P>0.05$ ).

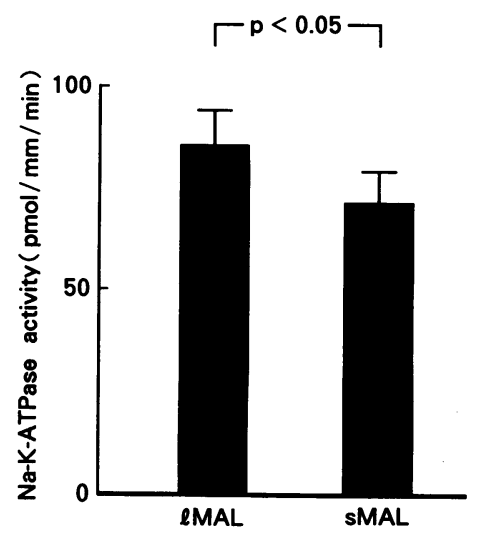

Figure 4. Na-K-ATPase activity in IMAL and SMAL. $\mathrm{Na}-\mathrm{K}-\mathrm{ATPase}$ activity was determined as described previously (26).
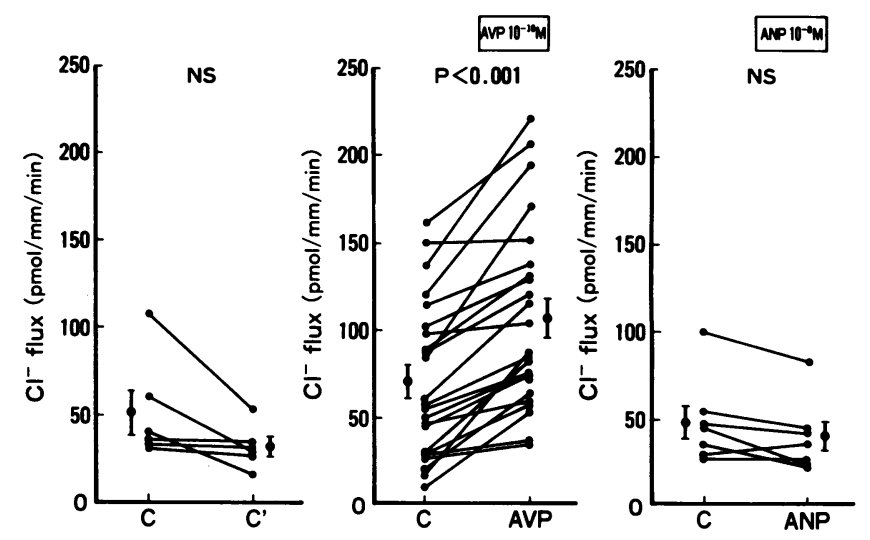

Figure 5. Effects of vehicle (left), $10^{-10} \mathrm{M}$ AVP (middle), and $10^{-8} \mathrm{M}$ ANP (right) on net $J_{\mathrm{C}}$ in IMAL. IMAL was dissected without collagenase treatment and perfused in vitro at $37^{\circ} \mathrm{C}$. AVP, ANP, or vehicle was added only to the bath solution. Chloride concentrations in the bath, perfusate, and collected fluid were measured using an ultramicrocolorimeter (30).

Effect of ANP on $J_{C l}$ in IMAL and SMAL in the absence of $A V P$ (Table I). The effect of ANP on $J_{\mathrm{C} 1}$ was studied in the absence of AVP. After the addition of ANP, $J_{\mathrm{Cl}}$ decreased in both IMAL and sMAL (from $48.2 \pm 9.3$ to $40.5 \pm 7.8 \mathrm{pmol} / \mathrm{mm}$ per min in IMAL and from $69.6 \pm 13.8$ to $50.7 \pm 14.8 \mathrm{pmol} / \mathrm{mm}$ per min in SMAL) (series 3 of Table I, right panel of Figs. 5 and 6). However, this change was not different from time controls in both IMAL and SMAL (by analysis of variance). Therefore, ANP alone did not affect $J_{\mathrm{Cl}}$ in both IMAL and sMAL.

Effect of $A N P$ on $J_{C l}$ in IMAL and SMAL in the presence of $A V P$. Next, the effect of ANP on $J_{\mathrm{C} 1}$ was examined in the presence of AVP. In SMAL, the addition of ANP and vehicle caused a decrease of $J_{\mathrm{Cl}}$ (from $73.2 \pm 10.1$ to $43.8 \pm 9.7 \mathrm{pmol}$ / $\mathrm{mm}$ per min by ANP and from $89.3 \pm 16.3$ to $54.3 \pm 11.7 \mathrm{pmol} /$ $\mathrm{mm}$ per min by vehicle) (series 4 and 5 of Table I, Fig. 8 ), but these decreases were not significantly different $(P>0.05)$. Stimulation of $J_{\mathrm{C}}$ by AVP in IMAL was sustained over time (series 6 of Table I, Fig. 9) (from 95.8 \pm 9.3 to $96.6 \pm 9.1 \mathrm{pmol}$ / $\mathrm{mm}$ per $\mathrm{min}$ ). $10^{-8} \mathrm{M}$ ANP reversibly inhibited AVP-stimulated $J_{\mathrm{C}}$ in $\mathrm{MMAL}$ by $30 \%(88.1 \pm 10.1,61.8 \pm 11.7$, and $72.1 \pm 9.9 \mathrm{pmol} / \mathrm{mm}$ per min, respectively, before, during, and
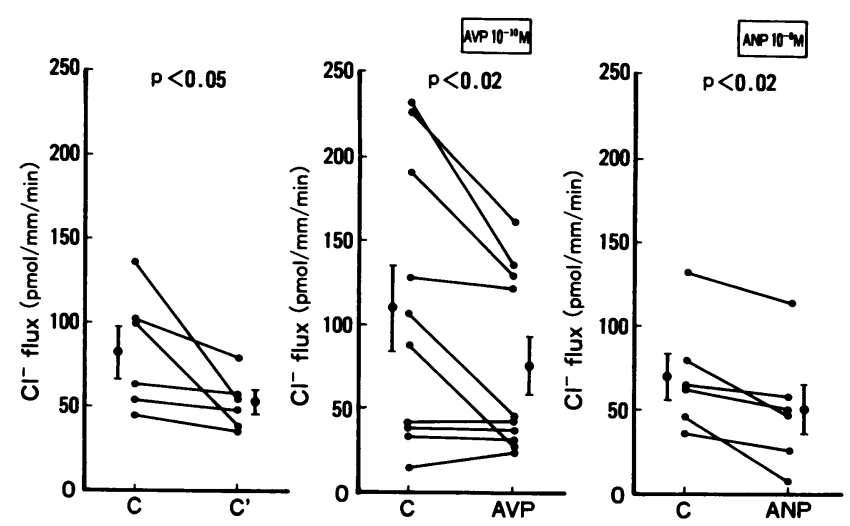

Figure 6. Effects of vehicle (left), $10^{-10} \mathrm{M} \mathrm{AVP} \mathrm{(middle),} \mathrm{and} 10^{-8} \mathrm{M}$ ANP (right) on net $J_{\mathrm{C}}$ in sMAL. 
Table I. Effects of $10^{-10} \mathrm{M} A V P$ and $10^{-8} \mathrm{M}$ ANP on Net Chloride Absorption in IMAL and SMAL

\begin{tabular}{|c|c|c|c|c|c|c|c|}
\hline & $\mathbf{L}$ & {$[\mathrm{Cl}]_{\mathrm{p}}$} & & NCR & {$[\mathrm{Cl}]_{c}$} & $J_{\mathrm{a}}$ & PD \\
\hline & $m m$ & $m M$ & & $\mathrm{nl} / \mathrm{mm}$ per min & $m M$ & $\mathrm{pmol} / \mathrm{mm}$ per min & $m V$ \\
\hline \multicolumn{8}{|c|}{ Series $1(\mathrm{C}=\mathrm{Control}, \mathrm{E}=\mathrm{Control})$} \\
\hline IMAL & $0.48 \pm 0.06$ & $116.6 \pm 0.7$ & C: & $12.6 \pm 4.2$ & $107.6 \pm 4.2$ & $51.5 \pm 12.1$ & $2.8 \pm 0.4$ \\
\hline$(n=6)$ & & & E: & $8.6 \pm 2.0$ & $109.7 \pm 3.2$ & $32.6 \pm 5.1$ & $1.9 \pm 0.2^{*}$ \\
\hline sMAL & $0.40 \pm 0.06$ & $117.6 \pm 0.8$ & C: & $17.5 \pm 6.9$ & $106.7 \pm 5.4$ & $82.8 \pm 14.5$ & $4.3 \pm 0.9$ \\
\hline$(n=6)$ & & & $\mathrm{E}:$ & $13.0 \pm 5.3$ & $109.3 \pm 4.2$ & $51.4 \pm 6.3^{*}$ & $3.0 \pm 0.8$ \\
\hline
\end{tabular}

Series $2\left(\mathrm{C}=\right.$ Control, $\mathrm{E}=10^{-10} \mathrm{M}$ AVP $)$

$\begin{array}{cccccccc}\text { IMAL } & 0.60 \pm 0.04 & 117.7 \pm 0.7 & \text { C: } & 9.8 \pm 1.1 & 107.7 \pm 1.6 & 70.8 \pm 9.2 & 2.6 \pm 0.2 \\ (n=23) & & & \text { E: } & 12.0 \pm 1.5 & 105.4 \pm 1.6^{*} & 107.8 \pm 11.0^{\S} & 3.3 \pm 0.3^{\S} \\ \text { sMAL } & 0.40 \pm 0.04 & 118.0 \pm 1.0 & \text { C: } & 14.5 \pm 1.9 & 109.6 \pm 2.0 & 109.8 \pm 24.6 & 3.2 \pm 0.5 \\ (n=10) & & & \text { E: } & 17.3 \pm 4.1 & 112.7 \pm 1.5^{*} & 75.4 \pm 16.3^{\ddagger}\end{array}$

Series $3\left(\mathrm{C}=\right.$ Control, $\mathrm{E}=10^{-8} \mathrm{M}$ ANP $)$

$\begin{array}{cccccccc}\text { IMAL } & 0.53 \pm 0.04 & 117.4 \pm 1.0 & \text { C: } & 7.5 \pm 1.6 & 106.2 \pm 5.5 & 48.2 \pm 9.3 & 3.1 \pm 0.8 \\ (n=7) & & & \text { E: } & 8.6 \pm 1.3 & 111.9 \pm 2.3 & 40.5 \pm 7.8 & 2.1 \pm 0.4 \\ \text { sMAL } & 0.51 \pm 0.05 & 112.4 \pm 1.8 & \text { C: } & 8.5 \pm 1.9 & 100.7 \pm 3.7 & 69.6 \pm 13.8 & 3.2 \pm 0.6 \\ (n=6) & & & \text { E: } & 7.9 \pm 2.1 & 105.6 \pm 2.1 & 50.7 \pm 14.8^{*}\end{array}$

Series $4\left(\mathrm{C}=10^{-10} \mathrm{M}\right.$ AVP, $\mathrm{E}=10^{-10} \mathrm{M}$ AVP $)$

$\begin{array}{cccccccc}\text { sMAL } & 0.40 \pm 0.03 & 116.9 \pm 1.0 & \text { C: } & 15.6 \pm 2.3 & 110.7 \pm 1.6 & 89.3 \pm 16.3 & 3.1 \pm 0.5 \\ (n=7) & & & \text { E: } & 12.9 \pm 2.1 & 111.9 \pm 2.1 & 54.3 \pm 11.7^{\S} & 2.5 \pm 0.6^{*}\end{array}$

Series $5\left(\mathrm{C}=10^{-10} \mathrm{M}\right.$ AVP, $\mathrm{E}=10^{-10} \mathrm{M}$ AVP $+10^{-8} \mathrm{M}$ ANP $)$

$\begin{array}{cccccccc}\text { sMAL } & 0.57 \pm 0.14 & 116.9 \pm 1.3 & \text { C: } & 4.9 \pm 1.7 & 94.7 \pm 5.9 & 73.2 \pm 10.1 & 3.1 \pm 0.3 \\ (n=6) & & & \text { E: } & 3.9 \pm 1.5 & 99.7 \pm 1.5 & 43.8 \pm 9.7^{\S}\end{array}$

Series $6\left(\mathrm{C}=10^{-10} \mathrm{M}\right.$ AVP, $\mathrm{E}=10^{-10} \mathrm{M}$ AVP $)$

$\begin{array}{cccccccc}1 \mathrm{MAL} & 0.50 \pm 0.06 & 116.0 \pm 1.1 & \mathrm{C}: & 15.7 \pm 2.6 & 108.8 \pm 1.8 & 95.8 \pm 9.3 & 3.6 \pm 0.5 \\ (n=11) & & & \text { E: } & 13.0 \pm 2.0 & 108.0 \pm 1.4 & 96.6 \pm 9.1 & 3.5 \pm 0.5\end{array}$

Values are mean \pm SE. Abbreviations: $\mathrm{C}$, control period; E, experimental period; $[\mathrm{Cl}]_{c}$, the concentration of chloride in collected fluid; $[\mathrm{Cl}]_{\mathrm{p}}$, the concentration of chloride in perfusate and bath; $J_{\mathrm{C}}$, net chloride absorption; L, tubular length; NCR, normalized collection rate; PD, transepithelial potential difference.

${ }^{*} P<0.05 ;{ }^{\ddagger} P<0.02 ;{ }^{\S} P<0.001$ (vs. control period).

after ANP, $n=8, P<0.01$ by paired $t$ test between the experimental value vs. the mean of control and recovery values; left panel of Fig. 10) and PD by $11 \%(3.6 \pm 0.5,3.2 \pm 0.5$, and $3.4 \pm 0.7 \mathrm{mV}$, respectively, before, during, and after ANP, $n$ $=10, P<0.05$; series 7 of Table II ). $10^{-10} \mathrm{M}$ ANP also inhibited AVP-stimulated $J_{\mathrm{C}}$ in IMAL by $26 \%(70.3 \pm 11.4$, $51.7 \pm 13.6$, and $59.0 \pm 16.0 \mathrm{pmol} / \mathrm{mm}$ per min, respectively before, during, and after ANP, $n=8, P<0.02$; middle panel of Fig. 10) and PD by $14 \%(3.7 \pm 1.3,3.2 \pm 1.1$, and $3.4 \pm 1.1 \mathrm{mV}$, respectively, before, during, and after ANP, $n=8, P<0.02$; series 8 of Table II). Finally, $10^{-4}$ to $10^{-5} \mathrm{M}$ cGMP significantly inhibited AVP-stimulated $J_{\mathrm{C}}(142.5 \pm 17.3,85.6 \pm 12.6$, and $105.6 \pm 9.5 \mathrm{pmol} / \mathrm{mm}$ per min, respectively, before, during, and after ANP, $n=6, P<0.01$; right panel of Fig. 10) and $\mathrm{PD}(3.7 \pm 0.3,3.3 \pm 0.3$, and $3.3 \pm 0.3 \mathrm{mV}$, before, during, and after ANP, respectively, $n=6, P<0.05$; series 9 of Table II).

\section{Discussion}

There has been interest in the past regarding the possibility of internephron heterogeneity $(22,23)$, i.e., differences between long- and short-looped nephrons. The structural and functional significance of having both long- and short-loop nephrons is still unclear. Bankir and de Rouffignac (23) have pointed out that there is a good correlation between the urineconcentrating ability and the degree of nephron heterogeneity; i.e., the juxtamedullary-to-superficial ratio for glomerular size, proximal tubule length, and single-nephron glomerular filtration rate is high in desert rodents. Concerning the heterogeneity of MAL, there have been no previous reports on functional differences between IMAL and sMAL. In fact, rarely have the two been distinguished (27), partially because of the technical difficulty in discriminating between them. Knepper (27) 

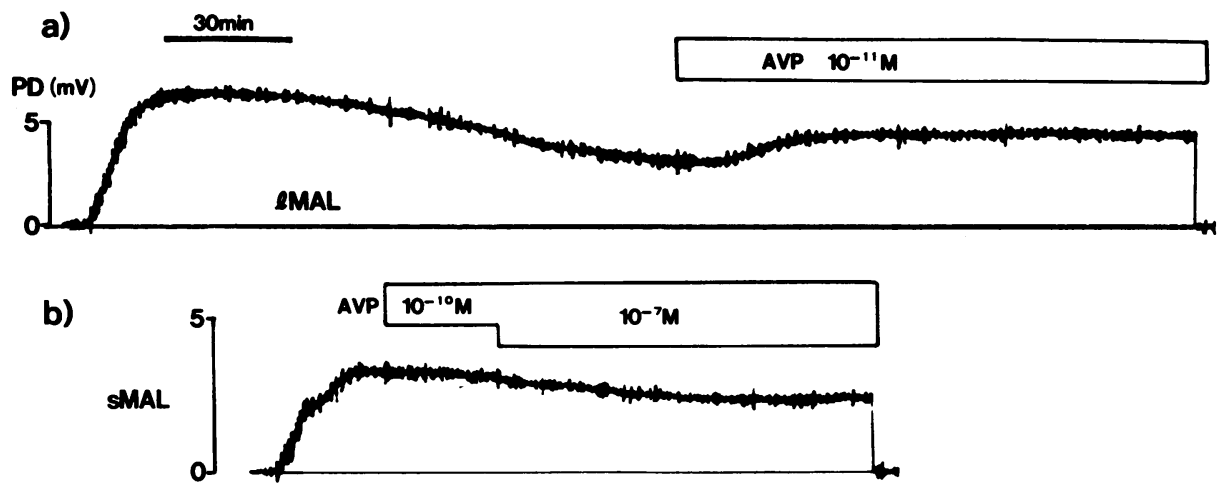

c)

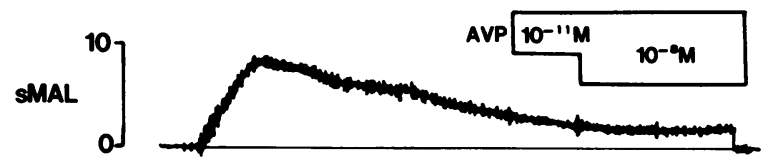

Figure 7. Effect of AVP on transepithelial PD in $(a)$ lMAL and $(b$ and $c)$ sMAL. AVP increased PD in IMAL. In sMAL, addition of AVP just after the peak of PD $(b)$ or during the decrease of PD (c) did not stimulate PD. showed that there was no difference in urea permeability between IMAL and SMAL.

In the present study, we have observed functional differences between MMAL and SMAL for the first time. Our results, showing differences in Na-K-ATPase activities; AVP-, glucagon-, and calcitonin-stimulated cAMP production; ANP-stimulated cGMP production; and AVP-stimulated electrogenic $J_{\mathrm{Cl}}$ in the two segments, raise the possibility that other functional differences may exist between the two. These findings may help to explain some apparent discrepancies in the literature. For example, although AVP stimulates adenylate cyclase in rat MAL (17), no effect of AVP was seen on $\mathrm{NaCl}$ transport in isolated perfused rat MAL (18). The negative result may have been obtained because predominantly SMAL were dissected. Good (31) reported an effect of AVP on bicarbonate transport and PD (possibly $J_{\mathrm{Cl}}$ ) in rat MAL. Furthermore, al-
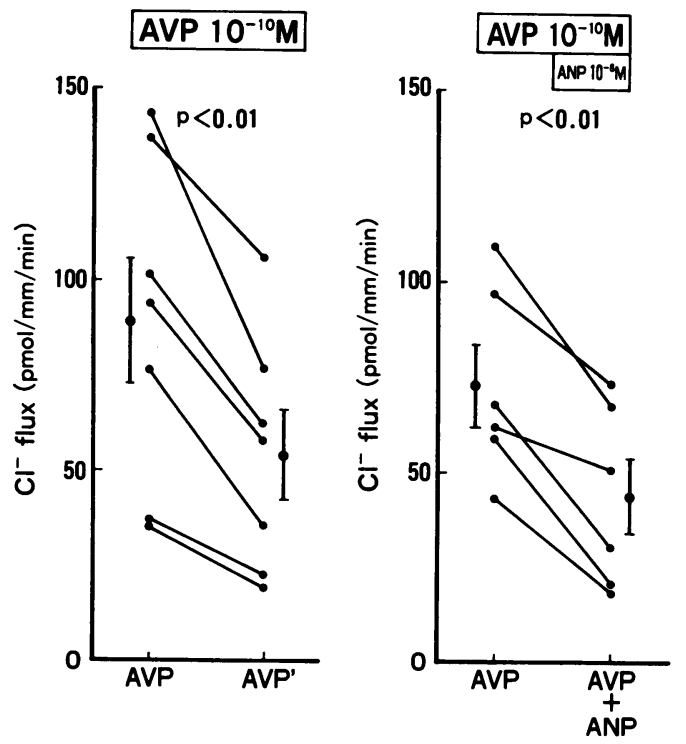

Figure 8. Effect of vehicle (left) and $10^{-8} \mathrm{M}$ ANP (right) on net $J_{\mathrm{G}}$ in the presence of $10^{-10} \mathrm{M}$ AVP in SMAL. ANP had no effect on $J_{\mathrm{C}}$ in sMAL in the presence of AVP. though AVP stimulates adenylate cyclase in MAL from rodents, no effect was seen on MAL from human kidneys (32). The ratio of short to long loops of Henle (sMAL/IMAL) in the rat is 70:30, while in the human it is much larger: 85:15 (23). Hence, if the same heterogeneity between SMAL and IMAL exists in the human and the rat, one would be less likely to see an effect of AVP on randomly dissected tubules. Thus, it is conceivable that AVP stimulates adenylate cyclase and electrogenic $J_{\mathrm{Cl}}$ in human MAL as in rat MAL.

Although Sasaki and Imai (18) could not find any stimulative effect of AVP on chloride transport, Work et al. (19) demonstrated an AVP effect on $J_{\mathrm{C}}$ in the Brattleboro rat, which lacks endogenous AVP. The response of $J_{\mathrm{C}}$ to AVP in our study may be somewhat weak and variable compared with the study by Work et al. (19). They did not need to wash out endogenous AVP, whereas we waited for 45-90 min for IMAL before the addition of AVP. During that period, $J_{\mathrm{C}}$ decreased with time. This may be one reason for the differences between their study and ours. Another reason is that we used only IMAL, whereas Work et al. might have used both IMAL and sMAL. The decrease of $J_{\mathrm{C}}$ with time may represent a gradual loss of stimulation by endogenous AVP. Sands et al. (29) reported gradual decreases of urea and osmotic water permeability with time in IMCD, suggesting a washing out of intrinsic AVP with time (29). The reason $J_{\mathrm{C}}$ decreased more rapidly in sMAL than in IMAL and why AVP did not stimulate $J_{\mathrm{C}}$ in sMAL is unclear. Kondo et al. (16) also reported a gradual decrease of $J_{\mathrm{Cl}}$ with time in rabbit MAL, in which AVP is known not to stimulate $J_{\mathrm{Cl}}$. Desensitization to AVP may be greater in rat SMAL and rabbit MAL. Na-K-ATPase activities did not decrease with time in both IMAL and SMAL. However, we still cannot exclude the possibility of decreasing $\mathrm{Na}-\mathrm{K}$ pump activity with time in $\mathrm{MAL}$ and SMAL, inasmuch Na-KATPase activity we measured means maximum activity in the presence of enough substrates, and some important metabolic substrates, such as ATP, may decrease more rapidly in sMAL than in IMAL. There must be some differences between IMAL and sMAL besides the data we showed. More studies are needed to learn why sMAL did not respond to AVP.

An important finding in the present study was that ANP 


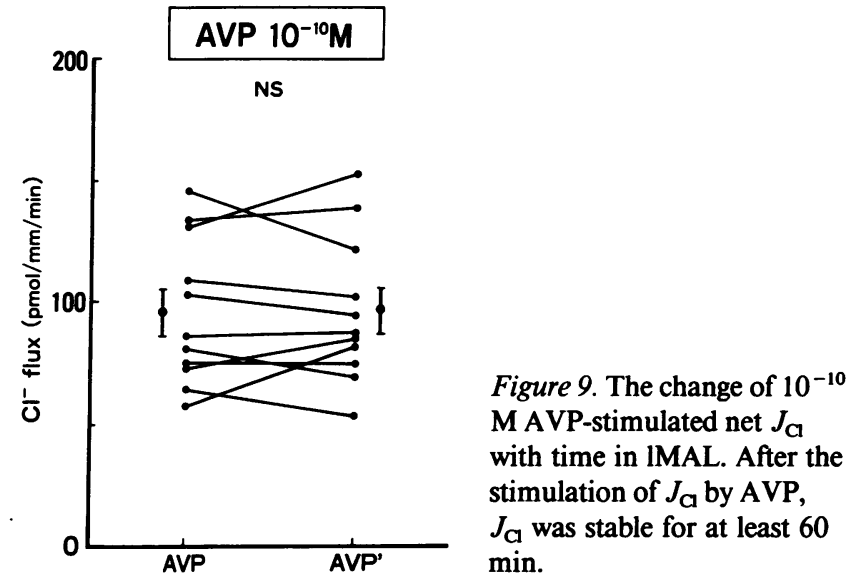

inhibits AVP-stimulated but not unstimulated electrogenic $J_{\mathrm{C}}$ only in IMAL. Because AVP did not stimulate $J_{\mathrm{C}}$ in SMAL, we may have failed to see any effect of ANP on $J_{\mathrm{C}}$ in sMAL. The effect of ANP on bicarbonate transport must be studied also in IMAL and SMAL, in that AVP is known to inhibit bicarbonate absorption in MAL (31). Based on previous studies, the chief sites of ANP action were thought to be in glomeruli, IMCD, and CCD $(1-13,24)$. Although ANP inhibits $\mathrm{Na}$ and fluid reabsorption in IMCD and CCD, which can contribute substantially to the natriuresis and diuresis of ANP, the results of micropuncture studies $(7,14,33)$ are consistent with a renal tubular effect earlier in the nephron. A selective effect of ANP on the juxtamedullary loop of Henle has been proposed in recent micropuncture studies (14). Our results appear to be consistent with this view, inasmuch as ANP caused a marked reduction in active $\mathrm{Cl}^{-}$absorption in MAL from juxtamedullary nephrons (IMAL). Because the rate of $\mathrm{NaCl}$ absorption in MAL is the largest among distal nephron segments and provides the chemical potential energy for the renal countercurrent multiplication system, even a small inhibition of $\mathrm{Cl}^{-}$ absorption could result in a large chloride excretion in the urine. ANP inhibited AVP-stimulated $J_{\mathrm{C}}$ in IMAL by $26-30 \%$ in the present study (series 7 and 8 of Table II, left and middle panels of Fig. 10). Taking into account that AVP increased $J_{\mathrm{C}}$ in IMAL by $50 \%$ (series 2 of Table I, middle panel of Fig. 5), the inhibition of $J_{\mathrm{C}}$ by ANP is thought to be $\sim 80-90 \%$ of AVP-induced increase of $J_{\mathrm{C}}$. Although Kondo et al. (16) reported that ANP did not inhibit $\mathrm{NaCl}$ transport in MAL from the rabbit, they did not distinguish between MAL and SMAL. Furthermore, because AVP is known not to stimulate $\mathrm{NaCl}$ absorption in the rabbit, they could not study the interaction between AVP and ANP. Recent studies have suggested that inhibition of ion transport by ANP is usually caused by an interaction with other hormones, such as AVP, angiotensin, and dopamine, which affect renal ion transport $(6,12,34-36)$. Our present data completely agree with these data. However, a direct effect of ANP on the Na channel in IMCD has been also reported (9).

The effect of ANP in this segment is thought to be mediated by cGMP, because cGMP mimicked the effect of ANP. Urinary cGMP is thought to be a biological marker of the renal activity of ANP (37). ANP increased cGMP accumulation in both IMAL and SMAL in the presence of phosphodiesterase inhibitor, IBMX. Terada et al. (38) reported the presence of guanylate-cyclase-coupled ANP receptors in MAL. However, the effect of ANP on cGMP accumulation in both IMAL and SMAL was undetectable without IBMX. More studies may be required to show clearly that cGMP is a second messenger of ANP in MAL. The second messenger of AVP for stimulating chloride absorption is CAMP. The interaction of the cAMP and cGMP systems in MAL is not known. In human fibroblasts, ANP reduces cAMP content by activating cAMP phosphodiesterase (39), but this mechanism seems to be specific to fibroblasts. Stimulation of protein kinase $C$ by endothelin is known to decrease AVP-stimulated cAMP synthesis in collecting ducts (40). However, ANP did not decrease AVP-stimulated cAMP synthesis in MAL (24). So, the mechanism of the inhibition of AVP action by ANP in MAL is still unknown. $\mathrm{NaCl}$ absorption in MAL is very high, whereas water permeability is
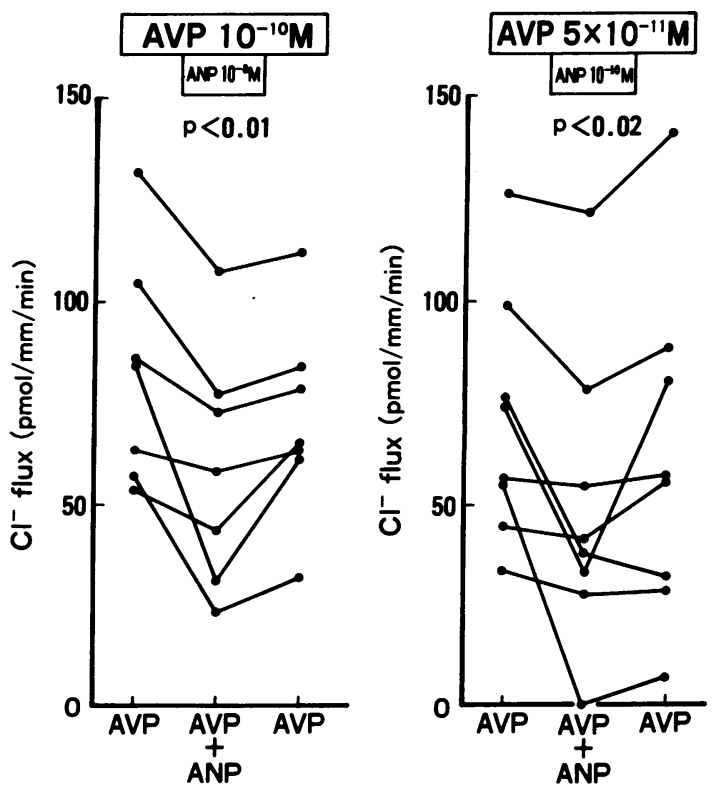

Figure 10. Effect of ANP (left and middle) and cGMP (right) on AVP-stimulated $J_{\mathrm{C}}$ in IMAL. AVP, ANP, and CGMP were added only to the bath. (•) $10^{-5} \mathrm{M}$ cGMP; (O) $10^{-4} \mathrm{M}$ cGMP. After changing the bath solution, at least 15-20 min was allowed to equilibrate to a new condition. Two to five collections were taken at each experimental condition and were averaged to obtain a single value. 
Table II. Effects of ANP and cGMP on AVP-stimulated Chloride Absorption in IMAL

\begin{tabular}{cccccc}
\hline $\mathrm{L}$ & {$[\mathrm{Cl}]_{\mathrm{p}}$} & $\mathrm{NCR}$ & {$\left[\mathrm{Cl}_{\mathrm{c}}\right.$} & $J_{\mathrm{C}}$ & $\mathrm{PD}$ \\
\hline $\mathrm{mm}$ & $\mathrm{mM}$ & $\mathrm{nl} / \mathrm{mm}$ per min & $\mathrm{mM}$ & pmol/mm per min
\end{tabular}

Series $7\left(\mathrm{C}, \mathrm{R}=10^{-10} \mathrm{M}\right.$ AVP, $\mathrm{E}=10^{-10} \mathrm{M}$ AVP $+10^{-8} \mathrm{M}$ ANP $)(n=7)$

$\begin{array}{lllllll}0.50 \pm 0.07 & 117.8 \pm 0.6 & \text { C: } & 7.9 \pm 1.3 & 105.8 \pm 2.0 & 88.1 \pm 10.1 & 3.6 \pm 0.5 \\ & & \text { E: } & 7.9 \pm 1.3 & 108.8 \pm 2.1^{*} & 3.8 \pm 11.7^{\S} & 72.1 \pm 9.9\end{array}$

Series $8\left(\mathrm{C}, \mathrm{R}=5 \times 10^{-11} \mathrm{M}\right.$ AVP, $\mathrm{E}=5 \times 10^{-11} \mathrm{M}$ AVP $+10^{-10} \mathrm{M}$ ANP $)(n=8)$

$\begin{array}{lllllll}0.57 \pm 0.08 & 117.0 \pm 1.4 & \text { C: } & 8.0 \pm 1.5 & 101.7 \pm 5.7 & 70.3 \pm 11.4 & 3.7 \pm 1.3 \\ & & \text { E: } & 8.8 \pm 1.6 & 105.3 \pm 5.6^{*} & 51.7 \pm 13.6^{\ddagger} & 3.2 \pm 1.1^{\ddagger} \\ & & \text { R: } & 8.2 \pm 1.5 & 104.5 \pm 5.5 & 59.0 \pm 16.0 & 3.4 \pm 1.1\end{array}$

Series $9\left(\mathrm{C}, \mathrm{R}=10^{-10} \mathrm{M}\right.$ AVP, $\mathrm{E}=10^{-10} \mathrm{M}$ AVP $+10^{-5}$ to $10^{-4} \mathrm{M}$ cGMP $)(n=6)$

\begin{tabular}{|c|c|c|c|c|c|}
\hline $0.61 \pm 0.09$ & $118.1 \pm 0.8$ & $11.7 \pm 1.4$ & $105.6 \pm 1.8$ & $142.5 \pm 17.3$ & $3.7 \pm 0.3$ \\
\hline & & $10.5 \pm 1.6$ & $108.6 \pm 2.8^{*}$ & $85.6 \pm 12.6^{8}$ & $3.3 \pm 0.3^{*}$ \\
\hline & & $11.4 \pm 1.6$ & $108.0 \pm 1.9$ & $105.6 \pm 9.5$ & $3.3 \pm 0.3$ \\
\hline
\end{tabular}

Abbreviations are as in Table I, except for the following: C, control period (AVP only); E, experimental period (AVP + ANP or cGMP); R, recovery period (AVP only).

${ }^{*} P<0.05 ;{ }^{\ddagger} P<0.02 ;{ }^{8} P<0.01$ (the value of the experimental period was compared with the mean value of the control and recovery periods).

quite low. Electrogenic $\mathrm{Cl}^{-}$reabsorption depends on at least four membrane transport pathways $(20,21)$ : an apical $\mathrm{Na}^{+}$$\mathrm{K}^{+}-2 \mathrm{Cl}^{-}$cotransporter, an apical $\mathrm{K}^{+}$channel, a basolateral $\mathrm{Cl}^{-}$channel, and Na-K-ATPase in the basolateral membrane. We have not studied the mechanism of this action. In theory, ANP could decrease electrogenic $\mathrm{Cl}^{-}$transport through effects on any of these pathways. Recently, an inhibitory effect of ANP on Na-K-ATPase activity in MAL has been reported (41). This could be one of the mechanisms of ANP action in IMAL. Measurements of intracellular electrical potential and ion activities will be required to resolve this issue.

It has been recently reported that the ANP-receptor/guanylate cyclase gene is a member of a family of membrane-bound guanylate cyclases whose extracellular domains function as peptide receptors (42). It is possible that a member of this family besides the ANP receptors is present in IMAL and may mediate inhibition of $\mathrm{NaCl}$ transport. Two possible physiological agonists for this receptor are brain natriuretic peptide (43) and urodilatin (44). It will be important to test whether these agents cause a greater increase in cGMP production and a greater inhibition of $\mathrm{NaCl}$ transport in this segment.

In summary, we showed that $\mathrm{MAL}$ is functionally different from sMAL and that ANP inhibits AVP-stimulated $J_{\mathrm{Cl}}$ in IMAL. $\mathrm{NaCl}$ reabsorption in this segment is the largest among distal nephron segments and is the source of the electrochemical potential energy that drives the countercurrent multiplication system. We propose that this effect may account for a significant part of ANP-induced natriuresis in vivo. Our data also support the importance of long-loop nephrons for urine concentration.

\section{Acknowledgments}

We sincerely thank Dr. Mark A. Knepper (National Institutes of Health) for critical reading of the manuscript and his continuous sup- port. We also thank Mr. Tomohiro Akada (Otsuka Electronics, Osaka, Japan) for making the ultramicrocolorimeter used in this study.

This study was supported by grants-in-aid for Scientific Research of the Government of Japan (02670273 and 02770326).

\section{References}

1. Cogan, M. G. 1990. Atrial natriuretic peptide. Kidney Int. 37:1148-1160.

2. Cogan, M. G. 1990. Renal effects of atrial natriuretic factor. Annu. Rev. Physiol. 52:699-708.

3. Ballermann, B. J., and B. M. Brenner. 1985. Biologically active atrial peptides. J. Clin. Invest. 76:2041-2048.

4. Knepper, M. A., S. P. Lankford, and Y. Terada. 1991. Renal tubular actions of ANF. Can. J. Physiol. Pharmacol. 69:1537-1545.

5. Mejia, R., J. M. Sands, J. L. Stephenson, and M. A. Knepper. 1989. Renal actions of atrial natriuretic factor: a mathematical modeling study. Am. J. Physiol. 257 (Renal Fluid Electrolyte Physiol. 26):F1146-F1157.

6. Nonoguchi, H., J. M. Sands, and M. A. Knepper. 1988. Atrial natriuretic factor inhibits vasopressin-stimulated osmotic water permeability in rat inner medullary collecting duct. J. Clin. Invest. 82:1383-1390.

7. Sonnenberg, H., U. Honrath, C. K. Chong, and D. R. Wilson. 1986. Atrial natriuretic factor inhibits sodium transport in medullary collecting duct. Am. J. Physiol. 250 (Renal Fluid Electrolyte Physiol. 19):F963-F966.

8. Zeidel, M. L., D. Kikeri, P. Silva, M. Burrowes, and B. M. Brenner. 1988. Atrial natriuretic peptides inhibit conductive sodium uptake by rabbit inner medullary collecting duct cells. J. Clin. Invest. 82:1067-1074.

9. Light, D. B., E. L. Schwiebert, K. H. Karlson, and B. A. Stanton. 1989. Atrial natriuretic peptide inhibits a cation channel in renal inner medullary collecting duct cells. Science (Wash. DC). 243:383-385.

10. Van de Stolpe, A., and R. L. Jamison. 1988. Micropuncture study of the effect of ANP on the papillary collecting duct in the rat. Am. J. Physiol. 254 (Renal Fluid Electrolyte Physiol. 23):F477-F483.

11. Rocha, A. S., and L. H. Kudo. 1990. Atrial peptide and cGMP effects on $\mathrm{NaCl}$ transport in inner medullary collecting duct. Am. J. Physiol. 259 (Renal Fluid Electrolyte Physiol. 28):F258-F268.

12. Dillingham, M. A., and R. J. Anderson. 1986. Inhibition of vasopressin action by atrial natriuretic factor. Science (Wash. DC). 231:1572-1573.

13. Nonoguchi, H., J. M. Sands, and M. A. Knepper. 1989. ANF inhibits $\mathrm{NaCl}$ and fluid absorption in cortical collecting duct of rat kidney. Am. J. Physiol. 256 (Renal Fluid Electrolyte Physiol. 25):F179-F186.

14. Fried, T. A., R. W. Osgood, and J. H. Stein. 1988. Tubular site(s) of action of atrial peptide in the rat. Am. J. Physiol. 255 (Renal Fluid Electrolyte Physiol. 24):F313-F316. 
15. Knepper, M. A., and M. B. Burg. 1983. Organization of nephron function. Am. J. Physiol. 244 (Renal Fluid Electrolyte Physiol. 13):F579-F589.

16. Kondo, Y., M. Imai, K. Kangawa, and H. Matsuo. 1986. Lack of direct action of $\alpha$-human atrial natriuretic polypeptide on the in vitro perfused segments of Henle's loop isolated from rabbit kidney. Pflugers Arch. Eur. J. Physiol. 406:273-278.

17. Morel, F. 1981. Sites of hormone action in the mammalian nephron. Am. J. Physiol. 240 (Renal Fluid Electrolyte Physiol. 9):F159-F164.

18. Sasaki, S., and M. Imai. 1980. Effects of vasopressin on water and $\mathrm{NaCl}$ transport across the in vitro perfused medullary thick ascending limb of Henle's loop of mouse, rat and rabbit kidneys. Pflügers Arch. Eur. J. Physiol. 383:215221.

19. Work, J., J. H. Galla, B. B. Booker, J. A. Schafer, and R. G. Luke. 1985. Effect of ADH on chloride reabsorption in the loop of Henle of the Brattleboro rat. Am. J. Physiol. 249 (Renal Fluid Electrolyte Physiol. 18):F698-F703.

20. Greger, R. 1985. Ion transport mechanisms in thick ascending limb of Henle's loop of mammalian nephron. Physiol. Rev. 65:760-797.

21. Hebert, S. C. and T. E. Andreoli. 1984. Control of $\mathrm{NaCl}$ transport in the thick ascending limb. Am. J. Physiol. 246 (Renal Fluid Electrolyte Physiol. 15):F745-F756

22. Valtin, H. 1977. Structural and functional heterogeneity of mammalian nephrons. Am. J. Physiol. 233 (Renal Fluid Electrolyte Physiol. 2):F491-F501.

23. Bankir, L., and C. D. Rouffignac. 1985. Urinary concentrating ability: insights from comparative anatomy. Am. J. Physiol. 249 (Regul. Integrative Comp. Physiol. 18):R643-R666.

24. Nonoguchi, H., M. A. Knepper, and V. C. Manganiello. 1987. Effects of atrial natriuretic factor on cyclic guanosine monophosphate and cyclic adenosine monophosphate accumulation in microdissected nephron segments from rats. $J$. Clin. Invest. 79:500-507.

25. Ujiie, K., H. Nonoguchi, K. Tomita, and F. Marumo. 1990. Effects of ANF on CGMP synthesis in inner medullary collecting duct subsegments of rats. Am. J. Physiol. 259 (Renal Fluid Electrolyte Physiol. 28):F535-F538.

26. Tomita, K., A. Owada, Y. lino, N. Yoshiyama, and T. Shiigai. 1987. Effect of vasopressin on $\mathrm{Na}^{+}-\mathrm{K}^{+}$-ATPase activity in rat cortical collecting duct. Am. J. Physiol. 253 (Renal Fluid Electrolyte Physiol. 22):F874-F879.

27. Knepper, M. A. 1983. Urea transport in isolated thick ascending limbs and collecting ducts from rats. Am. J. Physiol. 245 (Renal Fluid Electrolyte Physiol. 14):F634-F639.

28. Burg, M. B. 1972. Perfusion of isolated renal tubules. Yale J. Biol. Med. 45:321-326.

29. Sands, J. M., H. Nonoguchi, and M. A. Knepper. 1987. Vasopressin effects on urea and $\mathrm{H}_{2} \mathrm{O}$ transport in inner medullary collecting ducts. Am. $\mathrm{J}$. Physiol. 253 (Renal Fluid Electrolyte Physiol. 22):F823-F832.

30. Star, R. A., M. B. Burg, and M. A. Knepper. 1985. Bicarbonate secretion and chloride absorption by rabbit cortical collecting ducts: role of chloride/ bicarbonate exchange. J. Clin. Invest. 76:1123-1130.
31. Good, D. W. 1990. Inhibition of bicarbonate absorption by peptide hormones and cyclic adenosine monophosphate in rat medullary thick ascending limb. J. Clin. Invest. 85:1006-1013.

32. Chabardes, D., M. Gagnan-Brunette, M. Imbert-Teboul, O. Gontcharevskaia, M. Montegut, A. Clique, and F. Morel. 1980. Adenylate cyclase responsiveness to hormones in various portions of the human nephron. J. Clin. Invest. 65:439-448.

33. Briggs, J. P., B, Steipe, G. Schubert, and J. Schnermann. 1982. Micropuncture studies of renal effects of atrial natriuretic substance. Pflügers Arch. Eur. J. Physiol. 395:271-276.

34. Harris, P. J., D. Thomas, and T. O. Morgan. 1987. Atrial natriuretic peptide inhibits angiotensin-stimulated proximal tubular sodium and water reabsorption. Nature (Lond.). 326:697-698

35. Garvin, J. L. 1989. Inhibition of $\mathrm{J}_{\mathrm{v}}$ by ANF in rat proximal straight tubules requires angiotensin. Am. J. Physiol. 257 (Renal Fluid Electrolyte Physiol 26):F907-F911.

36. Winaver, J., J. C. Burnett, G. M. Tyce, and T. P. Dousa 1990. ANP inhibits $\mathrm{Na}^{+}-\mathrm{H}^{+}$antiport in proximal tubular brush border membrane: role of dopamine. Kidney Int. 38:1133-1140.

37. Wong, K. R., M. H. Xie, L. B. Liu, C. L. Huang, D. G. Gardner, and M. G. Cogan. 1988. Urinary cGMP as biological marker of the renal activity of atria natriuretic factor. Am. J. Physiol. 255 (Renal Fluid Electrolyte Physiol. 24):F1220-F1224.

38. Terada, Y., T. Moriyama, B. M. Martin, M. A. Knepper, and A. GarciaPerez. 1991. RT-PCR microlocalization of mRNA for guanylyl cyclase-coupled ANF receptors in rat kidney. Am. J. Physiol. 261 (Renal Fluid Electrolyte Physiol. 30):F1080-F1087.

39. Lee, M. A., R. E. West, and J. Moss. 1988. Atrial natriuretic factor reduces cyclic adenosine monophosphate content of human fibroblasts by enhancing phosphodiesterase activity. J. Clin. Invest. 82:388-393.

40. Tomita, K., H. Nonoguchi, and F. Marumo. 1990. Effects of endothelin on peptide-dependent cyclic adenosine monophosphate accumulation along the nephron segments of the rat. J. Clin. Invest. 85:2014-2018.

41. Syren, M. L., J. Fryckstedt, G. Snyder, A. Aperia, and P. Greengard. 1991 ANP (1-28) inhibits $\mathrm{Na}^{+} / \mathrm{K}^{+}$-ATPase activity in mTAL segments of rat. $\mathrm{J} . \mathrm{Am}$. Soc. Nephrol. 2:48a. (Abstr.)

42. Schulz, S., S. Singh, R. A. Bellet, G. Singh, D. J. Tubb, H. Chin, and D. L. Garbers. 1989. The primary structure of a plasma membrane guanylate cyclase demonstrates diversity within this new receptor family. Cell. 58:1155-1162.

43. Sudoh, T., K. Kangawa, N. Minamino, and H. Matsuo. 1988. A new natriuretic peptide in porcine brain. Nature (Lond.). 332:78-81.

44. Schulz-Knappe, P., K. Forssmann, F. Herbst, D. Hock, R. Pipkorn, and W. G. Forssmann. 1988. Isolation and structural analysis of "urodilatin," a new peptide of the cardiodilatin-ANP-family, extracted from human urine. Klin. Wochenschr. 66:752-759. 